\title{
The impact of modelling in informatics education on collaborative learning with school Intranets
}

\author{
Sigrid E. Schubert \\ Informatics XII - Didactics of Informatics, University of Dortmund, \\ D-44221 Dortmund, Germany. \\ schubert@cs.uni.dortmund.edu
}

\begin{abstract}
This paper examines the potential value of modelling in informatics education. Learners understand that they must collide with the principle restrictions when they use these artificially created model worlds which have now become real systems within their environments. Computer supported learning processes often fail because the learners do not understand the informatics models with which they directly or indirectly interact. Chances in German secondary schools made it possible for learners to collaborate in their learning, even when remote from each other in space or time. A research project that started at the University of Dortmund during the academic year 1998-99 investigated the detection of the difficulties of these learners. Useful observations about the experience and the technology used to support groups were made. The study showed that collaborative learning requires modelling skills and competencies of informatics. Therefore examples of typical modelling tasks are presented from the view of the needs of learners.
\end{abstract}

Keywords: Collaborative learning, Internet, school Intranet, informatics modelling, data security

\section{INTRODUCTION}

During the past few years, the teaching and learning in schools has changed significantly due to the influences of informatics. It is to be expected that the future development in the direction of pupil orientation and their ability to learn throughout their life is mainly supported by informatics. Experts describe this overall development as the Information Age. There is a 
contradiction between the requirements placed on pupils to master complex informatics systems and the lack of a standard, obligatory place in the school curriculum, which can be used for learning informatics. Nievergelt analysed this contradiction at Swiss schools and formulated the following observation: "In the age of applications, programming is no longer merely required as a tool but is basic knowledge for the reasonable application of tools produced by the others. A similar statement is just as valid for all forms of general education" (Nievergelt, 1999, p. 368). For this requirement which was disregarded for a very long time, a new type of informatics education must be tested that places the emphasis on the acquiring and construction of informatics models.

Hubwieser and Broy have introduced a special curriculum for this purpose: "The emphasis lies on the representation of information about complex systems, which we call modelling. In our opinion these techniques support the students in nearly all problem solving tasks, within informatics as well as within all other subjects" (Hubwieser \& Broy, 1999, p. 166). The term informatics modelling is used in this article in order to avoid confusion with the very narrow view of programming as a tool. Informatics modelling opens up general educational methods of access to the understanding of informatics systems. This article is linked to this knowledge and tries to illustrate how informatics education supports new school developments.

The informatics education working group at the University of Dortmund carried out research into:

-the basic concepts of informatics and their implementation in informatics education (Humbert, 1999),

-tele co-operation as an object and means for informatics education (Schubert, 1998; Schubert, 1999), and

-the development of collaborative learning via a school Intranet (Rüdiger, 1999).

The theoretical concepts was empirically examined in discussions with school heads and teachers, performance tests, by interviewing pupils and the video recording of lessons. It has been shown that informatics education has a strong influence on learning. This includes both the contents (Oberschelp, 1998) and the learning methods (Taylor, 1997). 


\section{MODELLING IN INFORMATICS}

\subsection{What is special about this way of modelling?}

Model formation and system development differ from other sciences enormously. Computer scientists construct descriptions (programs, software), which are designed to differentiate space for action. When required, the description is applied and it controls processes in the real world. These actions should not be left to coincidence but should turn human objectives into actions. This can only succeed if the real world is described in the informatics system as precisely as possible.

This is exactly the problem. In principal, informatics systems are only able to take in a specific part of the world they model. These synthetic sections form the model. It was always the case that the human being had to decide what was of importance for him in the case of a concrete application and what he could dispense with, or believed that he could go without. If the decisions are successful, then the user hardly notices that he is having an effect on real life by use of his model. He is satisfied if he completes his tasks, is able to achieve his objectives.

In the most unfavourable situation, the model proves to be useless. The informatics system cannot be implemented. Obviously, one hopes that such models can be amended and improved so that they can be used. However, there will always be some disagreement about the specific advantages and disadvantages that a model has in principle. The specification for the model is developed and it summarises the desired system characteristics. The correctness of a system is determined by comparing it with the specification.

The connections with the real world cannot be completely included for testing, as they can also not be fully included in the informatics model. Therefore, user demands are only taken into account if they are included in the specification. This influence at the system development stage is made more difficult for a class of tasks that are processed by persons who do not personally participate in the development process. Users are accordingly dissatisfied with solutions that are designed to cover large areas of responsibilities. Beginners find it difficult to understand that they must collide with the principle restrictions when they use these artificially created model worlds that have now become real systems within their environments.

\subsection{Informatics models provide general education}

Pupils are often not well prepared to take their future personal responsibility as emancipated citizens for the creation of the Information 
Age. They should deal with interactive media in a critical manner although they may never have learned how to understand them. If one analyses the mysteries of these systems, we have two basic problems:

1. The pupils do not have an application strategy which releases them from the specialities of the single systems and which, in principle, provides them with access to the solution of a task class which has a similar functionality. For this, a functional system model is required.

2. The expectations that the pupils have deviate from the real system situation so that a cognitive gap prevents the interpretation of the system process. To this end, a situation transition model supports the orientation in complex and non-deterministic process sequences.

The promotion of the basic understanding of informatics systems is one of the most important educational objectives of informatics education. We start with the simplest acquaintance of typical information and process sequence representation structures. The more demanding design function should not be missing. This has to do with an exemplary penetration of the development process. The best way to learn informatics modelling is in a handling-oriented manner. Knowledge of informatics structure concepts (Hubwieser \& Broy, 1999) which can be applied and modified is required for the transitions of sections from reality to model.

Computer-supported learning processes often fail because the pupils do not understand the informatics models with which they directly or indirectly interact. One example for the direct confrontation with an informatics model is the regulation of interaction rights. If the pupils understand the principles, methods, and tools, then they can to make and implement decisions independently. As far as selecting the functionality of classes in an objectoriented informatics system is concerned, the pupils only have an indirect access to the application model. The development team made decisions which can no longer be influenced within the learning process and it is possible that they can be restricting or impeding.

\section{CHANCES IN GERMAN SECONDARY SCHOOLS}

\subsection{Schools on the Internet}

In Germany, many teachers brought schools online long before mediaeffective campaigns existed for this purpose. Colleges and universities 
promoted the development of a school-specific telecommunication structure. Therefore, in the beginning teachers and pupils only had a restricted access to the Internet. The participants produced their electronic documents on the school computer without an active network connection. These documents were collected and stored in the world-wide network at regular intervals.

In the beginning, a small number of teaching projects made use of the new communication possibilities. The foreign language lessons in the subject English profited from the fast overseas e-mail. The collection and evaluation of environmental data required learning that encompassed both states and subjects. The discussion of globally political themes opened the way to intercultural learning.

Telecommunications leads to an opening up of the schools, provides access to new materials and opinions. It can promote the substantial growth of learning groups and the exchange of experiences between teachers. However, these potential advantages do not open up automatically but require new capabilities. The design of electronic documents, the effective search through the information offered world-wide, and the responsible handling of the action radius which is heavily expanded are all a part of this.

From 1996 to 1999 many schools which provided secondary education were connected to the world-wide Internet via a single telephone line and with only one single workstation (one single computer). For the approximately more than 1,000 pupils and more than 100 teachers at such a school it quickly became clear how unsatisfactory this situation was. Many teachers solved the problem by installing a Linux server themselves in order to connect the local school network to the Internet. A considerable number of regional and countrywide training courses about this subject took place as the inhomogeneous school technology made the administration much more difficult. In the meantime, the neglected school network administrators founded a regionally subdivided group in the German Informatics Society (GI) in order to bring about a reasonable level of support for this unpaid service and to promote the exchanging of experiences.

\subsection{Development of school Intranets}

The term school Intranet encompasses a wide range of performances. It is now the case that a local school laboratory is able to make internal and external use of Internet technology in almost all German secondary schools. Parents and teachers attempt to gain promotional funds for equipping additional rooms. Exemplary solutions exist which provide Intranet access from all classrooms and staff rooms. Learning concepts, which make use of this, are still rare. Good examples are presented via the regional education server and school presentations. 
Equipment recommendations were developed by the members of the aforementioned GI-Group. It is often the case that the school administration is overtaxed as far as making future decisions concerning the content and financial aspects. School failures with donated used company computers and discarded administrative computers did not help to save up money. It is amazing that so many teachers attempt to create or expand a school Intranet system in their free time. The support by school heads and colleagues is by no means routine. The replacement of missing concepts by technically enthusiastic teachers and pupils is only possible as a temporary measure.

At the time this article is being written in November 1999, the external access to learning materials on the school Intranet is still an exception for most of the pupils and teachers but the development here is so fast that the author expects that this access will be the normal situation in the near future. The typical situation today is that teachers and learners continue with their work at home, each for themselves. The networking of these homework stations has started. The exchange of experiences between the teachers is enriching. In learning processes, these networks are still playing a background role. The submission and return of homework is no longer carried out within the school. Solutions that can easily be copied must be analysed. Extensive collections of digital materials are being created in the schools. However, they are often very isolated next to the education concepts and hardly influence the overall school programme.

It is especially the case that as a form of preparation for life-long learning process, they enable new thinking and working methods to be created and must be anchored in the school profiles and curricula. Traditional tasks such as examination revision can be very effectively and individually supported. The unclear administrative tasks initially impair the systematic development of the existing school Intranet. There are still closed laboratories. School administration networks are organised and administered across all schools.

\subsection{Computer supported collaborative learning - CSCL}

The BSCW system (GMD, 1995-99) is a software system for CSCL in schools which is very comfortable to use and free of charge. It has been criticised by teachers for not being easy enough to use. CSCL is a sensitive process that requires complex models in order to provide support via divided systems which are independent of time and location. This gain in handling quality has its price. One is not concerned with highly complex informatics systems, but with the daily life at a secondary school. The spiral curricula which has made a name for itself over generations because it ranged from the simple to the complicated is confronted by the challenge of opening up the access of to these complexities which cannot be reduced by any means. 
The Dortmund didactics group researched CSCL in two initial stages. In the first case, CSCL was introduced to the informatics education as a tutorial package together with BSCW systems (Humbert, 1999). The motivation resulted from the founding of the concept and implementation of technically elaborate processes on the basis of general education. As far as this is concerned, ambitious informative educational content can be included in a handling-oriented manner, for example:

- the design of an order structure for the organisation of the information,

- the activation of system signals for group co-operation,

- the linking of internal and external information structures,

- the version check for information administration,

- the access rights for security demands typical for the group, and

- the working techniques for information transfer.

The pupils successfully learn how to use a model-based access.

In the second case, research was carried out into the transition from the traditional group work to CSCL with teaching material both in informatics lessons and in subject-specific projects. This research project was carried out within the scope of the pilot project to introduce the field of information and communication technology at a special kind of grammar schools in Saxony (1998-2002). In this project, a school form are being developed in Germany in which the "teaching of principles of informatics" was emphasised in the teaching-learning process in order to examine the influence of informaticsrelated thinking and working methods through all subjects.

The results of the CSCL in project training with Web-based systems showed an unusually high level of pupil motivation and independence (Rüdiger, 1999). The comparison with other developments showed that this positive experience is not dependent on a specific CSCL system (Leinonen et al, 1999) and that the limited view of the place of informatics systems in the school in the category of media formation is incorrect.

\section{SKILLS AND COMPETENCIES}

\subsection{Learning scenario}

CSCL promotes project work with the following phases: 1) motivation, 2 ) objective orientation, 3) planning and recording of the activities, 4) allocation of roles, 5) information acquisition, 6) selection of tools, 7) setting up of solution hypotheses, 8) recommendation of working strategies, 9) documenting the agreements, 10) designing the solution, 11) securing, 
presentation and evaluation of the results, and 12) reflection on the learning process.

Simpler exercises for accessing information, structuring information, and tending to information security details which enable a transfer from the computer supported group work are necessary prior to this complex learning scenario.

\subsection{Access to information}

The pupils analyse group learning processes so that they are able to implement elementary CSCL tasks such as reading, conveying, writing and complex actions such as the searching and administration of documents with a process-oriented model (e. g. action diagrams). The differentiation according to roles (e.g. owner of a document) within the group by access rights is presented. This includes changing the groups and roles.

Searching must be based on strategies and tools. The catalogues with numerous hierarchical levels are based on expertise, the search machines on staying power. Both of these are search systems which include rules for dealing with meta-information (e.g. search paths). In order to understand the directories, one must have an insight into their logical structure. Search machines form extremely large databases without being able to evaluate the usefulness of this flood of information to the user. Carefully considered criteria must be developed that can be used to restrict the range of the search and to control the automatic, blind search which the Web-crawling robots carried out. The information evaluation is researched on the basis of the possibility of checking information sources.

An allocation of meta-information to the documents thus displaying the processing of information in the group is concealed behind the administration. At all times, who or what has changed and when it was changed must be recognisable at all times. The version control achieves this in many systems but does not secure the legal and ethical protection. For this reason, the group's public area must be separated from the personal area which each pupil has. The pupils should be able to administer the access to their documents themselves so that they develop the responsibility for the authorship and sense of legality.

\subsection{Structuring of information}

The pupils learn how to construct complex structures from elementary information and how to apply them to networks, for example:

- trees for the directory structure in order to organise the files,

- graphs for planning multimedia documents, and 
- semantic networks for illustrating the workflow.

A basic understanding of the installation and functional method of distributed systems is preparation for the design of distributed documents as a linking of local documents on the school server with global modules on the Internet. The fault vulnerability of absolute information addresses is recognised and relative links are reduced via a calculation algorithm. The pupils collaboratively construct the knowledge which is new for them in the form of documents and software. The linking of learning to modelling and knowledge construction can be used in all subjects but the informatics education as a prerequisite for this requires a fixed place in the curriculum.

In informatics, CSCL is used in the project work in order to develop a complex piece of software within the workgroups. The members of the group initially develop their thoughts and suggestions for solutions within their personal network learning area. The group reaches agreement as to when the intermediate results (analysis, specification, draft, program module) are to be placed for discussion in the mutual area. After an evaluation has been successfully completed, the modules are connected to form the complete system and group documentation. Thus, the division of labour is much more successful by the production of documentation than in traditional group lessons, this being due to the fact that all members really are active (Schubert, 1998). The normally unattractive recording of the interface and design decisions reached becomes a necessary component of group communication due to the CSCL system and is now immediately available in the digitised form which is required at a later date. It simplifies the evaluation of the learning outcomes.

Group communications is a field of experience which the pupils have and which they can model themselves with informatics methods. Taking awareness as an example, they understand how the traditional possibilities of directing attention to alterations in the learning process can be implemented in CSCL by means of an informatics system. This commences with the addition of meta-information (e.g. notes as learning instructions, icons with a signal effect) to the documents. Pointer structures combine the workflow document with the learning results. Progress and omissions within the learning process become transparent for the complete group. By changing the roles between leading the discussion and participating in the discussion the pupils make use of various CSCL functions in order to argue, evaluate, and motivate. With this they learn to understand the various CSCL layers.

\subsection{Information security}

Requirements which are easy to understand but which are difficult to realise exist in the group communications: 
- It should not be possible to falsify the message.

- It should not be possible for confidential information to reach unauthorised persons.

- It should be possible to prove who a message comes from.

The pupils recognise the limits of information security and the risks for the group resulting from carelessness (e.g., passing the password on to others). They learn how to differentiate between securing against accidental events and against intentional attacks with the following basic threats:

- Loss of confidentiality leads to an unauthorised gaining of information.

- Loss of integrity means a falsification of information.

- Loss of availability makes itself known in the form of an impairment of informatics systems functionality (e.g., by viruses).

By protecting against access or encrypting information it is possible to ensure that only the group of persons who are intended to read the information are able to do so and that the information is unable to reach the destination in an altered form without this being noticed. Protection against access should completely, permanently and correctly guarantee access rights in accordance with security requirements which typical for the group. In a security strategy, the pupils determine which persons are permitted to carry out certain operations with certain objects. These rights and prohibitions must be controlled by the system on the basis of a database, in which the access rights are store. Therefore, mechanisms are required for the authentication (identification and verification) of group members on the basis of ownership, knowledge or biometric characteristics.

The pupils use the digital signature and acquaint themselves with the basic principle. Only the owner of a secret cipher key is able to create a signature. Every other person can use the public cipher key in order to determine whether the signature is genuine. Mathematical functions exist which are easy to compute with polynomial complexity, the reversal of which being practically impossible without additional information (called trap-door) being made available. One-way functions such as the factorising method and the discrete logarithm method can be used in a signature algorithm. After the document has been electronically prepared, the digital signature can be calculated and included. After the receipt of a signed document, the identity of the sender must be checked. One advantage is that the electronic signature is disconnected from each bit of the message, which is to be signed. For longer messages it makes sense not to sign the message itself, but a functional value of a certain length which can be allocated to it. This compression regulation is referred to as cryptographic hash function. 


\section{IMPLICATIONS FOR THE FUTURE}

CSCL provides the pupils with many ideas which must often be dealt with. It is often the case that the teacher has almost no time for the moderation of new group communications. A new learning culture looms. It requires adequate prevailing situations that are currently missing. It is typically the case that pupils and teachers separately continue with their work at home after mutual lessons have taken place. Work has commenced on the networking of these home workstations but in Germany, these are not yet connected with the school Intranet.

Collaborative learning requires transparent and understandable teachinglearning actions. Pupils are subjected to higher demands to the effect that they describe their actions and document their activities, them therefore being hardly able to withdraw in the group. Teachers must release themselves from routine methods, learn how to master new informatics systems and therefore notice that they have much more work dictated the preparation and evaluation of group learning.

Informatics modelling is experiencing a Renaissance and is becoming a prerequisite for successful projects, even outside informatics. However, this implies that the pupils who do not have suitable access to informatics education of this kind might have a negative attitude to learning. These application situations are not suitable for the trial-and-error method. The Department on Informatics Education of the German Informatics Society recommends a systematic introduction to the informatics modelling for all pupils from 10 years of age.

CSCL is an application process in which the pupils especially understand and actively co-design demanding informatics concepts. They are provided with a problem and handling-oriented system including abstract structures and complicated mechanisms for rights administration, awareness, workflow management, and data protection.

The capability of structuring information space in a network with informatics methods and navigating such structures in order to determine a required information with an acceptable level of effort is a part of the general education of all students in the Information Age. Pupils use informatics modelling in CSCL in order to structure their learning activities in an increasingly independent manner, to plan their learning process within their own responsibility, and to understand the curricula coherence better. It is exactly these capabilities which characterise life long learning. 


\section{REFERENCES}

GMD (1995-99) Basic Support for Cooperative Work (BSCW), http://bscs.gmd.de

Hubwieser, P., and Broy, M. (1999) Educating surfers or craftsmen: Introducing an ICT curriculum for the $21^{\text {st }}$ Century, in [ComNEd] Communication and Networking in Education in a Networked Society. Proceedings of the IFIP Open Conference, Aulanko, June 13-18, 115-121.

Humbert, L. (1999) Grundkonzepte der Informatik und ihre Umsetzung im Informatikunterricht. Informatica Didactica,[http://www.didaktik.cs.uni-potsdam.de/ InformaticaDidactica].

Leinonen T., Raami, A., Mielonen, S., Hakkarainen, K., and Muukkonen, H. (1999) FLE Tools Prototype: A WWW-based Learning Environment for Collaborative Knowledge Building, in [ComNEd] Communication and Networking in Education in a Networked Society. Proceedings of the IFIP Open Conference, Aulanko, June 13-18, 376-377 [http://mlab.uiah.fi/fle].

Nievergelt, J. (1999) Roboter programmieren - ein kinderspiel. Informatik-Spektrum, 22(5), 364-375.

Oberschelp, W. (1998) How informatics and discrete thinking return to school. in Information and Communications Technologies in School Mathematics (eds. D. Tinsley and D. Johnson), Chapman \& Hall, London.

Rüdiger, B. (1999) Von der traditionellen zur computerunterstützten Gruppenarbeit. LOGIN, 19(3/4), 36-41, [http://ls12-www.cs.unidortmund.de/ddi/forschung/ruediger].

Schubert, S. (1999) Informatische bildung und telekooperation. LOGIN, 19(3/4), 30-35.

Schubert, S. (1998) Internet-studies communication and information technology (CIT).

in Informatics in Higher Education (eds. F. Mulder and T. van Weert), Chapman \& Hall, London.

Taylor, H. (1997) Developing an active learning infrastructure with community involvement, telecommunications, and technology. it $+\mathrm{ti}$, Informationstechnik und Technische Informatik, 39(6), 27-32.

\section{BIOGRAPHY}

Sigrid Schubert received her diploma in physics from the University of Dresden (Germany) in 1972 and her doctoral degree in didactics of informatics from the University of Chemnitz in 1988. Since 1972 she has taught informatics in secondary and vocational education. In 1998 she became professor in didactics of informatics at the University of Dortmund. Her research interests are: informatics at secondary schools, collaborative learning, multimedia evaluation in teacher education. She is chairman of the Department on Informatics Education of the German Informatics Society (GI) and member in IFIP Working Group 3.1 on secondary education. 